\title{
Announcement
}

\section{Events in 2020}

The Korean Council of Science Editors announces the schedule of the events in 2020. The precise schedule and the registration information of the workshops were or will be available from: https://www.kcse.org

Table 1. Schedule of the events by the Korean Council of Science Editors in 2020

\begin{tabular}{|c|c|c|c|c|c|c|}
\hline & January & February & March & April & May & June \\
\hline Science Editing (twice a year) & & Vol.7 No.1 (20) & & & & \\
\hline Newsletter (4 times a year) & & & №. 33 (31) & & & No. 34 (30) \\
\hline Editor's Workshop & $\begin{array}{l}\quad 2020 \\
\text { Preconference } \\
\text { Workshop (17) }\end{array}$ & & & & & \\
\hline $\begin{array}{l}\text { Manuscript Editor's } \\
\text { Training \& Workshop }\end{array}$ & & & $\begin{array}{c}\text { Basic } \\
\text { Manuscript } \\
\text { Editing } \\
(12,19,26)\end{array}$ & $\begin{array}{c}\text { Basic } \\
\text { Manuscript } \\
\text { Editing } \\
(2,9,16,23,29) \\
\text { Manuscript } \\
\text { Editor's } \\
\text { Workshop (14) }\end{array}$ & & \\
\hline \multirow[t]{2}{*}{ Publication Ethics Workshop } & & & $\begin{array}{c}\text { Publication } \\
\text { Ethics } \\
\text { Workshop (30) }\end{array}$ & & & \\
\hline & July & August & September & October & November & December \\
\hline Science Editing (twice a year) & & Vol.7 No.2 (20) & & & & \\
\hline Newsletter (4 times a year) & & & №. $35(30)$ & & & No. 36 (31) \\
\hline Editor's Workshop & & & & & $\begin{array}{c}\text { Editor's } \\
\text { Workshop (20) }\end{array}$ & \\
\hline $\begin{array}{l}\text { Manuscript Editor's } \\
\text { Training \& Workshop }\end{array}$ & $\begin{array}{l}\text { Manuscript Editor's } \\
\text { Certificate } \\
\text { Workshop } \\
\text { (10-11) }\end{array}$ & & $\begin{array}{c}\text { Basic } \\
\text { Manuscript } \\
\text { Editing } \\
(15-16)\end{array}$ & & $\begin{array}{l}\text { Examination for } \\
\text { Korea Manu- } \\
\text { script Editors } \\
\text { Certification } \\
\text { (21) }\end{array}$ & \\
\hline Publication Ethics Workshop & & $\begin{array}{c}\text { Publication } \\
\text { Ethics } \\
\text { Workshop (21) }\end{array}$ & & & $\begin{array}{l}\text { Publication } \\
\text { Ethics } \\
\text { Workshop (27) }\end{array}$ & \\
\hline
\end{tabular}

